\title{
EFECTO DE LA PASTEURIZACIÓN Y LA TEMPERATURA DE INCUBACIÓN EN LA FERMENTACION ALCOHOLICA DEL MOSTO DE MORA
}

\section{EFFECT OF PASTEURIZATION AND INCUBATION TEMPERATURE IN THE ALCOHOL FERMENTATION OF MORA DE MORA}

\author{
${ }^{1 *}$ Leon C., Mariana C.; ${ }^{1}$ Jaimes Portilla, Jean
}
${ }^{1}$ Universidad de Pamplona, Facultad de Ingenierías y Arquitectura. Programa Ingeniería de Alimentos, Grupo de fundamentos de biotecnología. Km 1, Via Bucaramanga, Barrio El Buque, - Pamplona, Norte de Santander. Colombia. *Correo electronico: Carito mcl@hotmail.com

Recibido: 22 de Junio de 2017 ; Aprobado 30 Octubre de 2017

RESUMEN:

La fermentación alcohólica es un proceso anaeróbico en el cual intervienen microorganismos los cuales actúan dependiendo de las condiciones intrínseca y extrínsecas que sean expuesto. El presente estudio tuvo como objetivo evidenciar el efecto de la pasteurización y temperatura de incubación en la fermentación alcohólica de mostos a base de mora tipo castilla, obtenida de una finca de Pamplona, Norte de Santander. El mosto fue ajustado a solidos solubles de $15^{\circ}$ Brix y dividió en 2 pares de 2 litros. Una parte fue pasteurizada y la otra no, posteriormente se subdividieron cada parte en 2 para obtener, dos mostos pasteurizados y dos sin pasteurizar, a cada mosto se le adicionó 1 gramo de levadura enológica previamente hidratada. Dos de ellos 
(Pasteurizado y no pasteurizado) fueron llevados a temperatura de incubación de $30 \pm 2{ }^{\circ} \mathrm{C}$ y los otros a temperatura de $20 \pm 2{ }^{\circ} \mathrm{C}$. Se analizaron los grados Brix, $\mathrm{pH}$ y alcohol durante los días $0,3,8$ y 10. Los resultados incidieron que el mosto no pasteurizado e incubado a 30 $\pm 2{ }^{\circ} \mathrm{C}$ fue el que presentó mayor grado alcohólico, concluyendo que ésta es la temperatura óptima para desarrollar la fermentación alcohólica y que a pesar de que pasteurizar e inocular con la cepa de levadura puede es un buen "Starter" para producción de alcohol.

Autor a quien dirigir la correspondencias: León C. Mariana C.;. Correo electronico: Carito mcl@hotmail.com
Palabras claves: fermentación alcohólica, levadura, grados Brix, pasteurización, mora

\section{SUMMARY}

Alcoholic fermentation is an anaerobic process in which microorganisms intervene which act depending on the intrinsic and extrinsic conditions that are exposed. The objective of this study was to demonstrate the effect of pasteurization and incubation temperature in the alcoholic fermentation of musts based on mora type castilla, obtained from a farm in Pamplona, Norte de Santander. The must was adjusted to soluble solids of $15^{\circ}$ Brix and divided into 2 pairs of 2 liters. One part was pasteurized and the other was not, then each part was subdivided into 2 to obtain two pasteurized musts and two unpasteurized, to each must was added 1gr of previously hydrated yeast. Two of them (pasteurized and unpasteurized) were taken at incubation temperature of $30 \pm 2{ }^{\circ} \mathrm{C}$ and the others at a temperature of $20 \pm 2^{\circ} \mathrm{C}$. The Brix, $\mathrm{pH}$ and alcohol grades were analyzed during days $0,3,8$ and 10 . The results showed that the unpasteurized must and incubated at $30 \pm 2^{\circ} \mathrm{C}$ was the one with the highest alcohol content, concluding that this is the temperature optimal to develop alcoholic fermentation and that 
although pasteurizing and inoculating with the yeast strain can be a good "Starter" for alcohol production.

Key words: alcoholic fermentation, yeast, Brix degrees, pasteurization, blackberry

\section{INTRODUCCIÓN}

La fermentación alcohólica es un proceso anaeróbico en el cual intervienen microorganismos, estos transforman los azucares presentes en algunos alimentos en alcohol, dióxido de carbono, y energía. El proceso de fermentación es utilizado para la fabricación de bebidas alcohólicas tales como cerveza, vino, sidra, cava, sake, entre otras Arturo( 2014). El proceso de fermentación está caracterizado por un suave burbujeo (producción de $\mathrm{CO}_{2}$ ) el cual se intensifica durante los primeros cinco días y termina con la producción máxima de alcohol, lo cual ocurre entre la cuarta y quinta semana Márquez, (2004). Poco a poco el medio se va haciendo inhóspito para el desarrollo y supervivencia de las levaduras, debido a la formación de alcohol a la disminución de azucares y nutrientes necesarios para su desarrollo Collado, (2001). La fermentación alcohólica, etapa principal de la vinificación, es enteramente realizada por levaduras, generalmente de la especie Saccharomyces cerevisiae. Estas levaduras pueden ser consideradas como una materia prima en la elaboración del vino. Por lo tanto, es fundamental dominar la siembra, el crecimiento y supervivencia de estos microorganismos, a fin de asegurar una fermentación regular y completa. Como agentes responsables de la transformación del mosto en vino, debemos otorgar a las levaduras el mérito de expresar y crear los aromas, sabor y flavor que llevara nuestro vino. Un factor importante para la vida de las levaduras, no se desarrollan bien más que en una escala de temperaturas relativamente corta, 13 a $30^{\circ} \mathrm{C}$, las temperaturas mínimas y máximas dependerán de la especie de levadura que se use, si es resistente o no y cuál es la temperatura óptima para su desarrollo. También se deberá manejar la temperatura dependiendo del vino que se quiera obtener. Si se quiere obtener un vino con baja graduación alcohólica, se deberá hacer una fermentación a alta temperatura, por el contrario, si se quiere obtener un vino con alta graduación alcohólica se deberá proceder a una fermentación a baja temperatura. En general, la temperatura ideal para la vinificación en tinto se sitúa entre los 25 y los $30^{\circ} \mathrm{C}$, en función de la necesidad de conseguir una fermentación suficientemente rápida, una buena maceración y evitar el cese de fermentación. Para la vinificación en blanco 
la temperatura recomendada es más baja, alrededor de los $20^{\circ} \mathrm{C}$, Ruiz (1991).

La pasteurización es el proceso térmico realizado a líquidos (generalmente alimentos) con el objeto de reducir los agentes patógenos que puedan contener, tales como bacterias, protozoos, mohos y levaduras, etc. El proceso de calentamiento recibe el nombre de su descubridor, el científico químico francés Louis Pasteur (1822-1895). Uno de los objetivos del tratamiento térmico es la esterilización parcial de los alimentos líquidos, alterando lo menos posible la estructura física, los componentes químicos y las propiedades organolépticas de estos.

La mora de Castilla es originaria de las zonas altas tropicales de América principalmente de Colombia, Ecuador, Panamá, Guatemala, Honduras, México y El Salvador. El género Rubus es uno de los de mayor número de especies en el reino vegetal. La especie se cultiva en las regiones frías, entre 1800 y 2500 msnm, tiene gran aceptación para el consumo en fresco y procesado por su exquisito sabor y la facilidad de la agro industrialización. Produce una fruta apetecida, por ser rica en minerales y vitaminas, es altamente perecedera, por lo tanto, requiere de especiales cuidados durante la cosecha y el manejo pos cosecha Collado, (2001). La fruta está formada por múltiples drupas y dentro de cada drupa hay una semilla. Maduran de manera dispareja porque la floración no es homogénea. Cuando maduran su color va de rojo a púrpura (Franco y Giraldo, 2000). El objetivo de esta práctica es observar la variación en la fermentación alcohólica por el efecto de la pasteurización y la temperatura de fermentación de la mora.

\section{MATERIALES Y MÉTODOS}

Para la elaboración del jugo de mora, se empleó la mora tipo castilla, adquirida en una finca de pamplona, Norte de Santander.

El mosto fue ajustado a solidos solubles de $15^{\circ}$ Brix y dividió en 2 pares de 2 litros. Una parte fue pasteurizada y la otra no, posteriormente se subdividieron cada parte en 2 para obtener, dos mostos pasteurizados y dos sin pasteurizar, a cada mosto se le adicionó 1gramo de levadura enológica previamente hidratada. Dos de ellos (Pasteurizado y no pasteurizado) fueron llevados a temperatura de incubación de $30 \pm 2{ }^{\circ} \mathrm{C}$ y los otros a temperatura de $20 \pm 2{ }^{\circ} \mathrm{C}$ 


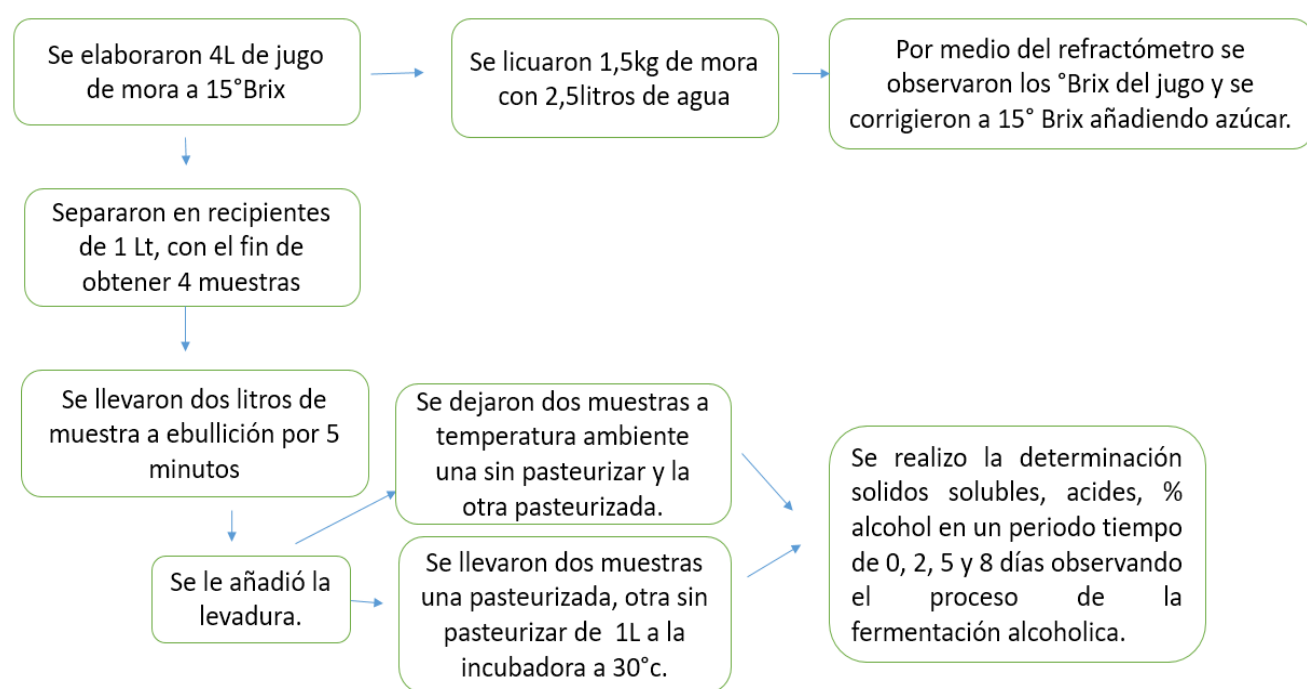

\section{RESULTADOS Y DISCUSIÓN}

Se realizó seguimiento al cabo de los 3,8 y 10 días de fermentación, llevando el control de $\mathrm{pH}$, grados de alcohol y grados Brix, como se detalla en la tabla 1.

Tabla 1. Resultados de la fermentación del jugo de mora.

\begin{tabular}{|l|l|l|l|l|}
\hline $\begin{array}{l}\text { \# y Tipo de } \\
\text { Muestra }\end{array}$ & Día & $\begin{array}{l}\text { Grados } \\
\text { GL }\end{array}$ & $\begin{array}{l}\text { Grad } \\
\text { os } \\
\text { Brix }\end{array}$ & $\begin{array}{l}\text { Acid } \\
\text { ez }\end{array}$ \\
\hline $\begin{array}{l}\text { 1. Past } \\
\text { eurizada ada } \\
30{ }^{\circ} \mathrm{C}\end{array}$ & Día 0 &, 0 & 15,0 & 2,19 \\
\cline { 2 - 5 } & Día 3 & 3,6 & 11,0 & 2,30 \\
\cline { 2 - 5 } & Día 8 & 5,0 & 5,0 & 2,45 \\
\cline { 2 - 5 } & Día 10 & 8,0 & 5,2 & 2,45 \\
\hline \multirow{2}{*}{$\begin{array}{l}\text { 2. Past } \\
\text { eurizada ambiente }\end{array}$} & Día 0 &, 0 & 15,0 & 2,19 \\
\cline { 2 - 5 } & Día 3 &, 0 & 13,2 & 2,51 \\
\cline { 2 - 5 } & Día 8 & 4,0 & 8,4 & 2,72 \\
\cline { 2 - 5 } & Día 10 & 7,0 & 7,5 & 2,64 \\
\hline \multirow{3}{*}{$\begin{array}{l}\text { 3. No } \\
\text { pasteurizada 30 C }\end{array}$} & Día 0 &, 0 & 15,0 & 2,75 \\
\cline { 2 - 5 } & Día 3 &, 0 & 9,0 & 2,27 \\
\cline { 2 - 5 } & Día 8 & 7,0 & 4,9 & 2,60 \\
\cline { 2 - 5 } & Día 10 & 10,0 & 4,9 & 2,60 \\
\hline \multirow{4}{*}{$\begin{array}{l}\text { 4. No } \\
\text { Pasteurizada } \\
\text { al ambiente }\end{array}$} & Día 0 &, 0 & 15,0 & 2,75 \\
\cline { 2 - 5 } & Día 3 &, 0 & 14,0 & 2,59 \\
\cline { 2 - 5 } & Día 8 & 6,6 & 6,0 & 2,57 \\
\cline { 2 - 5 } & Día 10 & 6,6 & 6,0 & 2,64 \\
\hline
\end{tabular}

En la figura 1. Se muestra la evolución del aumento de alcohol durante la fermentación, se puede observar que las muestras con mayor contenido de alcohol al final del proceso son las llevadas a una temperatura de incubación de $30^{\circ} \mathrm{C}$, cabe resaltar que de estas dos, la pasteurizada fue la que presentó un aumento de alcohol anticipado mientras la no pasteurizada después de que inició mantuvo un proceso constante y uniforme. 


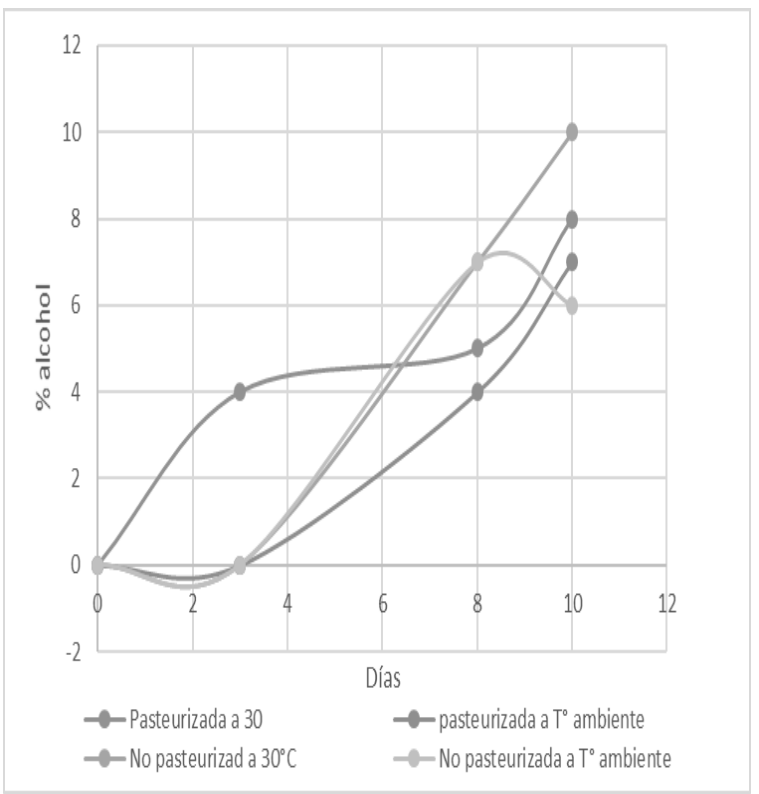

Figura 1. Aumento del alcohol en el proceso de fermentación.

\section{Evolución de los grados Brix durante}

\section{la fermentación alcohólica}

En la figura 2. Complementamos y corroboramos la información suministrada por la figura 1, pues podemos observar que la muestra 2, pasteurizada a temperatura ambiente, en pamplona un promedio de $18^{\circ} \mathrm{C}$, como fue la de menor porcentaje de alcohol, a su vez es la que mantiene la mayor cantidad de solidos solubles.

Se puede evidenciar que la pasteurización afectó la producción de alcohol, debido claramente al contenido de microorganismos contenidos en la fruta y el ambiente, limitando la tarea de fermentar únicamente a la cantidad de levadura añadida, sin embargo, el factor más relevante, es el de la temperatura a la que se lleva a cabo el proceso, obteniéndose la disminución de grados Brix más pronunciada en las muestras llevadas a temperatura de $30^{\circ} \mathrm{C}$.

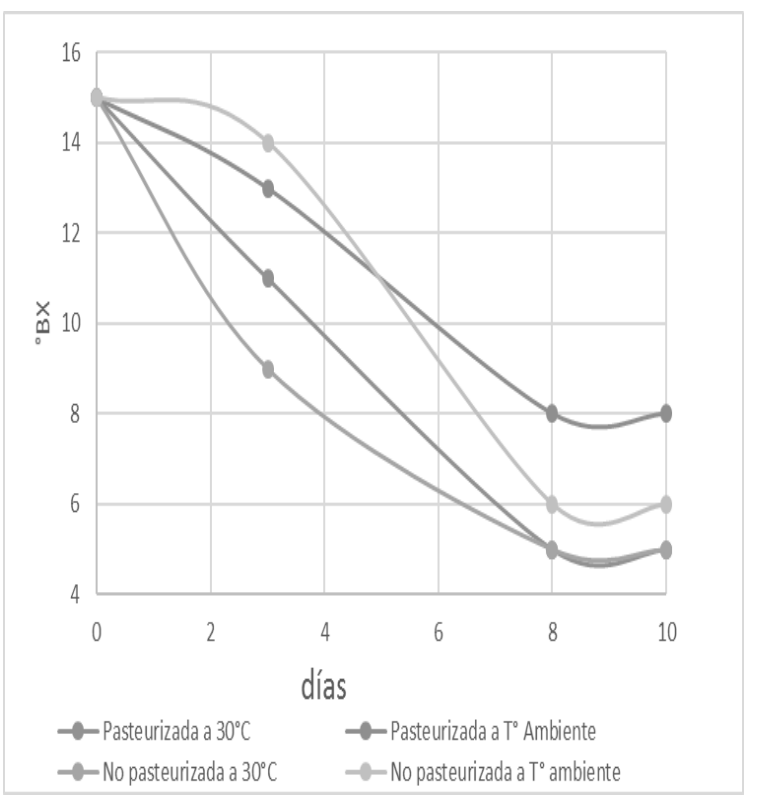

Figura 2. Disminución de Grados Brix vs días de fermentación.

La temperatura óptima para la fermentación alcohólica es tratada por (J. M \& M. T, 1999) donde sostiene que "las levaduras tienen en los $30^{\circ} \mathrm{C}$ su temperatura óptima de desarrollo. Por encima de los $35^{\circ} \mathrm{C}$ la actividad decrece rápidamente y en torno a los $45^{\circ} \mathrm{C}$ mueren. Por debajo de $10^{\circ} \mathrm{C}$ la mayor parte de las levaduras silvestres son inactivas".

Por otra parte, en un estudió similar de jugo de naranja natural y otro pasteurizado, sometido a fermentación ocurre lo mismo en cuanto a la producción de alcohol temprana por parte de la muestra pasteurizada e incubada, donde citan a Nurgel et al., (2002) quienes han demostrado que trabajando con jugo de uva 
pasteurizado e inoculando con una cepa autóctona de $S$. cerevisiae, "el consumo inicial de azúcares totales fue alto, pero a los 10 días la concentración de azúcares finales no alcanzó los niveles del producto de la fermentación de mosto no pasteurizado, presentando un remanente de $1,4 \mathrm{~g} / \mathrm{I}$ contra $1 \mathrm{~g} / \mathrm{l}$ del pasteurizado" (Ferreyra, et al., 2009). Situación que ocurrió y que es evidenciada en la figura 1.

\section{CONCLUSIONES.}

Las muestras pasteurizadas presentaron menor consumo de azúcares reductores, por tanto, menor producción y obtención de alcohol.

Por otra parte, la incubación a $30{ }^{\circ} \mathrm{C}$ permitió un desarrollo óptimo de la fermentación alcohólica, obteniéndose en las muestras incubadas mayor porcentaje de alcohol, no obstante, cabe resaltar que pasteurizar e inocular con una sola cepa de levadura puede ser un buen "Starter" aunque esta producción de alcohol se verá ralentizada y superada por el mosto no pasteurizado.

\section{REFERENCIAS BIBLIOGRAFICAS}

Arturo, M. c. (2014). Productos de la fermentación alcohólica; un. http://bibliotecadigital.usb.edu.co/bitstream /10819/2613/1/Fermentaci\%C3\%B3n\%20 alcoh\%C3\%B3lica\%20un\%20proceso_Car los\%20Contreras_USBCTG_2015.pdf.

Collado, Quique. Levadura y fermentación alcohólica I, 2001. http://www.verema.com/opinamos/tribuna/ articulos/levaduras01.asp.

Ferreyra, M. M., Schvab, M. d., Gerard, L. M., Zapata, L. M., Davies, C. V., \& A, H. R. (2009). Fermentación alcohólica de jugo de naranja con S. cerevisiae. scielo.
J. M, M., \& M. T, A. (1999). El papel de los microorganismos en la elaboración del vino. Journal of Food, 174-183.

Franco, G. y Giraldo, M. J. El cultivo de la mora. 3ed. Manizales: ICA, 2000.

Madrid, V. A. Y Madrid, C. J. Tecnología y legislación del vino y bebidas derivadas. Madrid, España: Mundi Prensa, 1994. 335 p.

Maldonado, M. Lida Y. y Caballero, P. Luz A. (2016). Bebida fermentada a base de arroz con adición de probióticos. Revista @limentech, Ciencia y Tecnología Alimentaria. ISSN 1692-7125. Volumen $14 N^{\circ}$ 1. Pp. $59-74$. 
Tirado A. Diego F. (2015). Elaboración de una bebida láctea a base de lactosuero fermentado usando streptococcus salivarius ssp., thermophilus y lactobacillus casei ssp. Case. Revista @limentech, Ciencia y Tecnología Alimentaria. ISSN 1692-7125. Volumen 13, No 1. Pp. 13 19.

Ruiz, Vinificación en Tinto, Editorial MundiPrensa, 1991. 